\title{
Investigating and Explaining the Role of Positive Psychology Components on the Organizational Entrepreneurship among the Faculty Members of Payame Noor University
}

\author{
Mehdi Esmaili \\ MSc in Executive Management, University of Science \& Technology, Iran \\ DOI< 10.26821/IJSRC.8.2.2020.8203>
}

\begin{abstract}
Adopting the entrepreneurial roles and utilizing the human resources' capacities and capabilities to create competitive advantage is seen as a necessity in today's world. In this regard, psychological capital is an important factor to achieve this goal. Accordingly, the present study aimed to investigate the structural model of the relationship between psychological capital components with organizational creativity and entrepreneurship. For this purpose, 385 faculty members of Payame Noor University constitute the statistical population of this study among them, a sample of 193 students was selected ûsing Cochran formula. The questionnaire, Pearson correlation coefficient and structural equation modeling (SEM) were used for data collection and analysis. Based on the results of structural equation modeling, there is a direct relationship between hopefulness and selfefficacy with creativity. There is also a direct and significant relationship between self-efficacy, hopefulness, resilience, optimism, and creativity with organizational entrepreneurship. Also, creativity plays a role as a mediating variable in the relationship between hopefulness and self-efficacy with organizational entrepreneurship. That is to say, hopefulness and self-efficacy affect organizational entrepreneurship with the mediating role of creativity. Keywords: Positive Psychology, Creativity, Organizational Entrepreneurship, Payame Noor University
\end{abstract}

Mehdi Esmaili, Vol 8 Issue 2, pp 7-16 February 2020

\section{Introduction}

As a new approach to psychology, positive psychology focuses on understanding and describing happiness and the subjective sense of well-being, as well as accurate prediction of the factors affecting them. From the positive psychology perspective, health index is not limited to the absence of mental illness symptoms; however, adaptation, happiness and self-esteem and positive traits like them indicates the healthy status and the main purpose of the person's life should be the improvement of his/her abilities. Therefore, considering the person's positive psychological aspects positive psychologists emphasizes on positive traits and growth of individual abilities. An indicator of positive psychology is psychological capital, which is defined by characteristics such as persons' ability to succeed, perseverance in pursuing goals, creating positive selfesteem, and tolerating problems (Luthans, 2007, 60). Psychological capital enables individuals to be less stressed, more capable to deal with problems, to have a clearer self-view, and to be less affected by daily events in addition to cope better with stressful situations. Seligman argues that psychological capital encompasses the positive aspects of one's life. He believes that human and social capital is open, easily visible, and can be easily measured and controlled. While psychological capital is more potential, it is difficult to measure and develop. Thus, psychological capital is defined as one's perception of oneself, the goal of achieving success and resilience to problems. Psychological capital is a hybrid, interconnected 
Volume 8 Issue 2 February 2020

construct that encompasses the four components of cognitive-cognitive hope, self-efficacy, and resilience, optimism. These components, in an interactive and evaluative process, give meaning to a person's life, continue the effort to change stressful times, prepare him or her to enter the scene of action, guaranteeing his or her resistance and tenacity in achieving goals. This, hopefully, is a positive motivation with clear goals for life. In the hope, on the one hand, there is the motivation to seek the will to move toward the goals and on the other hand to explore the appropriate ways to achieve the goals (SeyyedAbadi, 99: 2008).

Also, self-efficacy is judged by one's ability to perform an action. Optimism, in turn, means having positive expectations for outcomes and outcomes, and these outcomes are considered constant, general, and internal factors. Resilience is also a positive adaptation to responding to adverse conditions. Resilience is not merely passive resistance to harm or threatening conditions. Rather, the resilient person is the active participant and builder of their surroundings. Organizational entrepreneurship, on the other hand, is the process that the organization takes to enable all employees to perform in an entrepreneurial role and to carry out all individual or group activities consistently, quickly and easily in the central organization. It also includes fostering entrepreneurial behavior in an already established organization and the process by which innovative services or processes and organizational entrepreneurship are created to create entrepreneurial culture within an organization (Cultural, 2007: 46). Organizational entrepreneurship consists of three major components: innovative change, the creation of a new service within the existing structure, a fundamental transformation in the current structure through improvement, modification, shortening, integration or deletion of processes and procedures. Hence the need to use as much as possible all of the tangible and intangible assets and assets in order to make the organization more effective in the current research examining the role of psychological capital components in entrepreneurship within faculty members of Payam Noor University of Fars Provinces, we will pay for Bushehr and Hormozgan.

\section{2. positive psychology}

Positive psychological capital or positive psychology is a concept put forward by Fred Lutz, First, and his colleagues by combining positive psychological states of development and positive organizations. In fact, psychological capital is rooted in the framework and criteria of positive organizational behavior. In fact, positive organizational behavior is an approach and a general framework for concepts with high characteristics. According to this view, Lutz put forward the concept of positive organizational behavior in order to focus on the strengths and capabilities of employees that influence performance. The positivist approach in the workplace does not negate problem solving and pathology, but believes that such issues can be resolved in the light of positivism with less cost, time, and resistance. So the main idea of this approach is to focus on the strengths and capabilities (human resource development) rather than focusing on the weaknesses and treatment of HR problems - the traditional management paradigm (Lutz, 41: 2010). To date, research has advocated self-efficacy, hope, flexibility, and optimism as the structures that most conform to high standards. Research shows that the sum of these constructs is more influential, and in fact, there is a synergy between these concepts, and when we analyze all four components at the same time, we gain more impact. According to research and theorizing, the concept of psychological capital goes beyond human capital and social capital, encompassing, linking, and ultimately creating, and synergizing with, them. It is a better estimator of employee commitment and job satisfaction. Also, research indicates that psychological capital on job attitudes (job attitudes, job satisfaction, organizational commitment, etc.) behavior (organizational citizenship behavior, deviant behavior, aggression, etc.), emotions and moods. (Stress, depression, etc.), cognitive modes (problem solving, creativity, etc.) and especially individual and organizational work performance have a significant impact. Therefore, developing and managing psychological capital is critical for organizations, industries, businesses, and services to increase productivity and performance, and is an appropriate tool for effective management of individual and organizational outcomes. Also, compared to 
personality traits and characteristics and abilities that are partially constant (such as the Big Five personality traits, central self-assessment, IQ, etc.), psychological capital is a state-of-the-art, and therefore extensible and educational. Sun is a very useful and vital element in creating a lasting advantage for contemporary organizations.

The idea states that "although awareness of the psychological characteristics that are most often associated with a person's personality can be a general predictor of finding the right person for the role, but sometimes positive psychological states (psychological capital) are involved. They can be a better predictor of the successful implementation of a given role and even of its growth (Silva, 2010: 28). In addition, given that psychological capital is transferable, organizational leaders and managers can enhance employees' psychological capital as a model by increasing their psychological capital. Analyzes also indicate that the rate of return on investment caused by investing in psychological capital is significantly higher. The existence of standardized measurement tools and a high rate of return on capital adds to the validity of this theory and suggests that psychological capital is not a simple matter.

Lutz and his colleagues have found that by improving their psychological capital in the organization, their performance can be improved by at least $10 \%$. Organizational entrepreneurship is one of the variables in the organization that can improve the performance of the organization with the influence of psychological capital. In the following, we examine the role of psychological capital components on organizational entrepreneurship.

\section{2-1. Intra-Entrepreneurship}

According to Webster's Glossary, an entrepreneur is committed to organizing, managing, and undertaking the risk of an economic activity. "Robert Hysrich sees the process of creating entrepreneurship as something new, with the time and effort required, and the acceptance of financial, spiritual, Social to obtain financial resources is personal satisfaction and independence, which results from regular activities that link creativity and innovation to market needs and opportunities. According to him, entrepreneurship is the process of creating something new and valuable by running a business and dedicating the time and effort required, taking financial and social risks, to personal satisfaction, to financial rewards. And satisfying the need for independence (Lutz, 321: 2007).

Fry believes that intra-organizational entrepreneurship is the process by which innovative products (services) or processes are created by the creation of entrepreneurial culture in an organization. It is a process in which innovated products or processes emerge through the instillation and creation of entrepreneurial culture in a pre-established organization (Kuratko, 2004: 91). Organizational entrepreneurship operates within the organization and structures, approaches, Expands or adopts new norms, technologies, services and products of the organization.

Sharma (1990) define organizational entrepreneurship as the process by which individuals or groups of individuals present and create within a new organization, department, or organization, or an innovation or innovation within an organization. And. Moghimi et al. (2005) describe organizational entrepreneurship as the development of competencies and opportunities within the organization through various combinations of new resources. In fact, organizational entrepreneurs can create a significant competitive advantage for the organization. In the context of the importance of organizational entrepreneurship in organizations, Pinkett (2003) referred to organizational entrepreneurship as the "renaissance of organizations". He also argues that organizational entrepreneurship is not only possible and possible, but also critical to organizational success. However, it is also important to consider the underpinnings of human capital's entrepreneurial capacity. Organizational entrepreneurship is also seen as a process by which all employees can perform their role as entrepreneurs, and that all individual or group activities are continually, quickly and easily centralized in the organization. In addition, it involves entrepreneurial behavior within an organization that is already established and is a process that creates innovative services or processes and creates an entrepreneurial culture within an organization. Entrepreneurship is a process in which services are created through the creation of an entrepreneurial 
Volume 8 Issue 2 February 2020

culture within. An active organization is being developed (Antonik, 2003: 24). Positive Psychology and Intra-Entrepreneurship

Positive psychology is a new concept recently introduced by Lutans that derives from positive organizational behavior that can provide sustainable competitive advantage for organizations. Lutz (2002), the pioneer of positive organizational behavior, positively utilizes workplace empathy to focus on and enhance employees' abilities. And their psychological capacities define and state that such behaviors must include measurable and extensible constructs and be used to improve performance.

Psychological capital is created when the individual has not yet entered a business and needs to be developed at the stage when the individual launches the business or enters the organization or organization. Psychological capital is one of the key factors in predicting the entrepreneurial orientation in an organization that is more influenced by different levels of education and access to opportunities. There are two key factors with respect to all indicators of psychological capital: First, they can all be developed through experience and learning (who will you be) in addition to measuring the status quo (who are you?). That the level of development of these indicators varies among individuals and depends on their habits, and secondly, each of the indicators recognized in psychological capital alone leads to improved performance in individuals within an organization. Numerous studies indicate a positive relationship between the level of psychological capital and entrepreneurship and the creativity and innovation of employees.

The results of some research indicate that the total psychological capital is greater than its set of members, namely self-efficacy / self-confidence, hope, optimism, and flexibility. House (2004) showed that psychological capital alone predicts individuals' economic success. He acknowledged in his study that psychological capital predicted more than any other type of capital, such as social, intelligence, financial or material capital. Entrepreneurial risk and business success. Wall et al., In a study on psychological capital and entrepreneurial spirit development, found that this capital had a positive and significant effect on entrepreneurial spirit. Theoretical studies of psychological capital also argue that there is a positive relationship between psychological capital and organizational performance. For example, from the perspective of Adams et al. (2002),

hope has a positive and significant relationship with the performance of athletes and academics. In another study, he concluded that higher-level employees were more likely to look for opportunities for success and would have greater commitments than others in doing their job in the organization. Also, according to Patterson and Lutz (2003), the level of hopefulness of catering managers was positively correlated with unit financial performance, job satisfaction of their employees, and the tendency to staff entrepreneurship. Mill Ski and Work (2009) conducted a study examining the relationship between entrepreneurial psychological capital and the performance of newly established investment organizations. In their research, they concluded that there was no significant relationship between tangible capital such as financial and human capital and entrepreneurial performance of the organizations concerned, while at the same time there was a positive and meaningful relationship between psychological capital and organizational entrepreneurial performance. Environmental dynamics can be discovered. In another study (Lutans et al., 2007), which examined the relationship between entrepreneurial psychological capital and job satisfaction and its impact on entrepreneurial behavior, they found that there was a positive and meaningful relationship between psychological capital and job satisfaction. And increases the level of job satisfaction among employees to provide them with entrepreneurial behavior. Research has shown that employees in organizations with a positive attitude of optimism, optimism and resilience in the workplace, have a high level of performance and also have increased job satisfaction (Dahlaji, 171: 2010). In domestic researches, Forouhar et al. (2011), while confirming the positive and significant relationship between psychological capital and organizational entrepreneurship, stated that none of the components of this capital alone are estimators of organizational entrepreneurship. The results of the studies of Ali Akbar Ahmadi et al (2013) also indicate the relationship between each of the dimensions of 
Volume 8 Issue 2 February 2020

psychological capital with organizational organizational entrepreneurship, this study attempts to entrepreneurship. examine the relationship between the components of

\section{Research purposes}

Given the novelty of the concept of psychological capital and its effects on employees' creativity and psychological capital with organizational creativity and entrepreneurship in a three-level conceptual model.

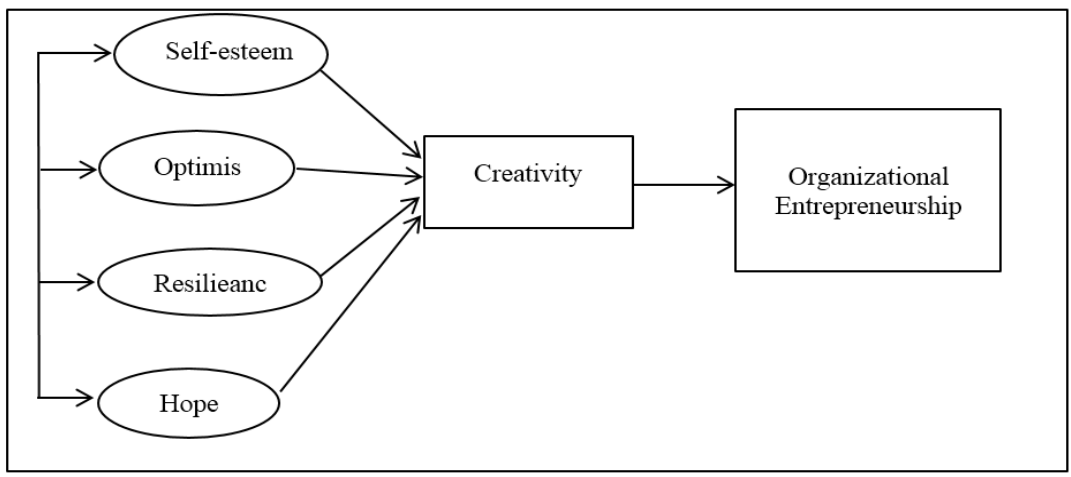

Figure 1: Conceptual model of research

\section{3-1. Research assumptions}

- The structural model of the relationship between the components of psychological capital (self-efficacy, hope, resilience, and optimism) with creativity and entrepreneurship within faculty members of Payam-eNoor University of Fars, Bushehr and Hormozgan Provinces has a good fit with the data.

\section{Research Methodology}

The purpose of the present study is to investigate the relationship between psychological capital and organizational entrepreneurship. In addition, researchers seek to determine how each of the four components of psychological capital (self-confidence, optimism, resilience, and hope) is related to psychological capital among faculty members. Payame Noor University of Fars, Bushehr and Hormozgan Provinces. Therefore, the present study is descriptive in terms of purpose, data collection method and type of correlation. The statistical population of this study consisted of 385 faculty members of Payam Noor University in Fars, Bushehr and Hormozgan provinces. The sample size was 193 using Cochran formula. Data were collected through two questionnaires of psychological capital and organizational entrepreneurship. After collecting the questionnaires, 7 equivalent questionnaires $(3.4 \%)$ were omitted due to inconsistencies in the answers and thus the sample reached 184 persons. The following tools were also used to measure variables:

Psychological Capital Questionnaire: The Lutz et al. Psychological capital questionnaire was used to measure psychological capital. The questionnaire uses standardized values that have widely used structures that measure hope, resilience, self-efficacy, and selfefficacy, and have validated the reliability and validity of these subscales. The questionnaire consisted of 24 questions and each subscale consisted of 6 items and the subjects answered each item on a 6-point Likert scale (strongly disagree to strongly agree). To obtain the psychological capital score, each subscale score was calculated separately and then summed as the total psychological capital score. In addition, the reliability of the questionnaire through Cronbach's alpha for self-efficacy, hope, resilience and optimism was $86 \%, 82 \%, 71 \%$ and $62 \%$, respectively, which indicates high validity and reliability of the test.

Organizational Entrepreneurship Questionnaire: The instrument for collecting this variable was a 55question questionnaire consisting of two parts $\mathrm{A}$ and B. It has been calculated. In addition, data were analyzed using Pearson correlation coefficient and structural equation modeling (SEM). Analyzes were performed using SPSS software and torque structure analysis software (AMOS). 
Volume 8 Issue 2 February 2020

\section{Research Findings:}

The mean, standard deviation and internal correlation between the research variables are presented in Table

Table 1: Mean, standard deviation and internal correlation between the research variables

\begin{tabular}{|c|c|c|c|c|c|c|c|c|}
\hline 5 & 4 & 3 & 2 & 1 & SD & $\mathbf{M}$ & $\begin{array}{l}\text { Research } \\
\text { variables }\end{array}$ & \\
\hline & & & & - & $0 / 76$ & $4 / 4$ & Efficacy & 1 \\
\hline & & & - & $0 / 7 * *$ & $0 / 81$ & $4 / 4$ & Hope & 2 \\
\hline & & - & $0 / 67 * *$ & $0 / 64 * *$ & $0 / 77$ & $4 / 43$ & Resilience & 3 \\
\hline & - & $0 / 52 * *$ & $0 / 62 * *$ & $0 / 54 * *$ & $0 / 73$ & $4 / 16$ & Optimism & 4 \\
\hline - & $0 / 61 * *$ & $0 / 43 * *$ & $0 / 63 * *$ & $0 / 51 * *$ & $1 / 42$ & $4 / 59$ & Creativity & 5 \\
\hline $0 / 67 * *$ & $0 / 47 * *$ & $0 / 33 * *$ & $0 / 6 * *$ & $0 / 52 * *$ & $0 / 62$ & $3 / 5$ & $\begin{array}{c}\text { Organizational } \\
\text { Entrepreneurship }\end{array}$ & 6 \\
\hline
\end{tabular}

According to the results in Table 1, the four components of self-efficacy, hope, resilience, and optimism have a positive and significant relationship with organizational creativity and entrepreneurship. It should be noted that the proposed model (Fig. 1) has been investigated using structural equation modeling. Therefore, given that an appropriate pattern should be non-significant in terms of the fitted two-factor XI, the ratio of the $X 2$ to the degree of freedom less than 2 , the goodness-of-fit index (GFI) and the comparative fit index (CFI) greater than 0.95 , The incremental fit index (IFI) is greater than 0.9 , the root mean square residual (RMR) is less than 0.05 and the root mean square error (RMSEA) is less than 0.08 (Myers, Gamst, \& Guarino, 2006). Initial proposed XI model was twice as high as 55.95 and significant $(\mathrm{P}$ $<0.01)$. However, despite the fact that GFI, CFI, IFI and RMSR are at the desired cutoff level, the significance of $X 2$, the high ratio of $X 2$ to the degree of freedom, and the RMSR greater than the optimum point indicate that the proposed model needs to be revised (Myers et al., 2006). Thus, based on the investigation of the path coefficients of the initial model with correction indices, it is necessary to make the following revisions to the proposed model:

Two paths from self-efficacy and resilience to creativity are removed and four paths from selfefficacy, hope, resilience and optimism to life. These paths were added to the final and revised model based on research background and correction indices (Myers et al. 2006; Nelson \& Cooper, 2007; Joseph \& Lutz, 2007; Lutz et al. 2008). Table 2 presents the results of the structural equation modeling for the final and revised research model:

Table 2: Results of Structural Equation Modeling for Final Research Pattern

\begin{tabular}{|c|c|c|c|c|c|c|c|c|c|c|c|c|}
\hline 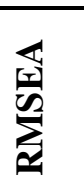 & $\sum_{\underline{a}}^{\mathscr{a}}$ & 鳥 & 穵 & 它 & & $\begin{array}{ll}x^{2} \\
(\text { (df) }\end{array}$ & & $\infty$ & $\frac{[-1}{d)}$ & 0 & $\begin{array}{c}\text { The relationship of variables } \\
\text { in the final model }\end{array}$ & \\
\hline & & & & & & & & $0 / 54$ & $0 / 09$ & $0 / 95$ & HopeCreativity & 1 \\
\hline & & & & & & & $0 / 40$ & $0 / 13$ & $0 / 1$ & $0 / 25$ & EfficacyGretivity & 2 \\
\hline & & & & & & & & $0 / 47$ & $0 / 02$ & $0 / 2$ & $\begin{array}{l}\text { CreativitOrgenizational } \\
\text { Entrepreneurship }\end{array}$ & 3 \\
\hline \multirow[t]{4}{*}{ 0/000 } & $0 / 002$ & 1 & 1 & 1 & $0 / 07$ & $0 / 15$ & & $0 / 23$ & $0 / 05$ & $0 / 17$ & $\begin{array}{l}\text { HopeOrgational } \\
\text { Entrepreneurship }\end{array}$ & 4 \\
\hline & & & & & & & $0 / 52$ & $0 / 19$ & $0 / 04$ & $0 / 15$ & $\begin{array}{l}\text { ResilienceOranizational } \\
\text { Entrepreneurship }\end{array}$ & 5 \\
\hline & & & & & & & & $0 / 12$ & $0 / 04$ & $0 / 1$ & $\begin{array}{l}\text { Efficacy@rgenizational } \\
\text { Entrepreneurship }\end{array}$ & 6 \\
\hline & & & & & & & & $0 / 16$ & $0 / 05$ & $0 / 13$ & $\begin{array}{l}\text { OptimismOanizational } \\
\text { Entrepreneurship }\end{array}$ & 7 \\
\hline
\end{tabular}


As can be seen in Table 2, two variables of hope and self-efficacy, with beta coefficients of $0.54,0.13$, and 0.40 , respectively, have been derived from variance of creativity. Next, creativity, hope, resilience, selfefficacy, and optimism with standard beta coefficients of $0.47,0.23,-0.19,0.12,0.16$, and 52.8 .8 of organizational entrepreneurship variance, respectively. Have explained. The general model derived from structural equation modeling is presented in Figure 2. However, the final model fit indices (Fig. 2) as seen in Table 2, the two final models $\mathrm{Xi}=0.158$ and non-significant $(\mathrm{p}<0.05)$, the
$\mathrm{X} 2$ ratio to the degree of freedom equal to 0.079 , GFI is 1 , RMSR is 0.002 and RMSEA is zero. The final and revised templates are presented.As can be seen in Figure 2, the two components of hope and selfefficacy, in addition to being directly related to creativity, also relate to creativity and organizational entrepreneurship. Therefore, these two components of psychological capital also have indirect effects that need to be identified. The indirect effects of hope and self-efficacy through creativity are presented in Table 3.

Table 3: Indirect and indirect effects of the final model of research in standard and nonstandard mode

\begin{tabular}{|c|l|l|r|}
\hline \multicolumn{2}{|c|}{$\begin{array}{l}\text { Organizational } \\
\text { Entrepreneurship }\end{array}$} & \multicolumn{1}{|c|}{ Indirect effects } & \\
\hline Standard & Non-standard & & \multicolumn{1}{|c|}{} \\
\hline & & $\begin{array}{l}\text { The Indirect Effect of Hope on Organizational } \\
\text { Entrepreneurship through Creativity }\end{array}$ & 1 \\
\hline & $\begin{array}{l}\text { The indirect effect of self-efficacy on organizational } \\
\text { entrepreneurship through creativity }\end{array}$ & 2 \\
\hline
\end{tabular}

As can be seen in Table 3, the indirect effects of hopefulness on organizational entrepreneurship through creativity in the non-standard form are 0.1 and in the standard form 0.12. In addition, the indirect effects of self-efficacy on organizational entrepreneurship through non-standard creativity is 0.17 and standard deviation is 0.23 . This coefficient based on available resources based on the Bootstrap test (Myers et al., 2006) is significant at $\mathrm{p}<0.01$ (often coefficients greater than 0.08 at $\mathrm{p}<0.01$ ). Also, the study of the mediating effects suggest that creativity is a link between hope and self-efficacy with partial mediating organizational entrepreneurship.

\section{Discussion and conclusion}

The purpose of this study was to investigate the structural model of the relationship between psychological capital components with organizational creativity and entrepreneurship. Payam Noor University of Fars, Bushehr and Hormozgan provinces have a positive and significant relationship. These results are in line with psychological theories, which state that the components of psychological capital in humans create capacities that affect levels of happiness, satisfaction, and success (Haboff 2002; Lutz Et al., 2007).

The results of structural equation modeling indicate that there are four components of self-efficacy, hope, resilience, and optimism with creativity and then with organizational entrepreneurship. In the first part of the model, unlike what was predicted in the initial conceptual model (Figure 1), only the two components of self-efficacy and hope with creativity had a significant relationship. In explaining this part of the findings, it can be stated that hope is a cognitive-motivational construct that is formed by the interaction of three main components of targeting, branding, and crossing (resolving ability) and is successfully related. In such a way that success in achieving goals, positive emotions and failure in it, creates negative emotions. Another point is that optimism and pessimism affect how individuals adjust to life events and their subjective expectations when faced with problems and how they behave when overcoming problems (McGee, 2011). Waiting for 
Volume 8 Issue 2 February 2020

inclusive results to be positive can be an important determinant of creativity among faculty members of Payame Noor University and thus organizational entrepreneurship. Another point was the lack of a significant relationship between resilience and creativity in the final and revised research model. Based on the results, it is likely that employee creativity is a hopeful phenomenon and is influenced by positive or negative explanatory styles.

The second part of the relationships found in the final model of the present study relates to the four components of self-efficacy, hope, resilience, and optimism alongside organizational creativity and entrepreneurship, which, as illustrated in figure two, creativity alongside the four components of psychological capital. It has the highest standard coefficient for entrepreneurship within the faculty of Payame Noor University. As such, creativity continues to play a major role in explaining organizational entrepreneurship, while also being a part of the relationship between self-efficacy and hope with organizational entrepreneurship. These two findings suggest that creativity, after being reinforced through self-efficacy and hope, extends its positive effects to organizational entrepreneurship. This overflow exemplifies the effect of creativity with organizational entrepreneurship with this explanation and viewpoint in psychological resource theory that positive constructs are foundational, central, and expandable resources that are at all moments with the individual to act in different situations. Accompanying and then forming a sense of accomplishment and happiness in individuals (Habofel, 2002). Simply put, creativity alongside self-efficacy, hope, resilience, and optimism is a major positive psychological resource that has a partial or complete mediating role for positive motivational, emotional, and cognitive constructs (self-efficacy, hope, resilience, and optimism). Nose) and overflow potential has a positive effect on entrepreneurship in various dimensions.

Empirical theorists such as (Larsen \& Lutzen, 2006; Joseph \& Lutzen, 2007; Lutzen et al., 2007; Nelson \& Cooper, 2007; Lutzen et al. 2008; Renshaw et al. 2010 and Delige et al. 2010) emphasize human and The potential capacities that will be realized by focusing on them have put a humanistic perspective on the improvement and excellence of human life in the various fields it strives to. From this perspective, the findings of this study indicate that such a positive attitude to psychological capacities plays a significant role in creativity and entrepreneurship. In other words, self-efficacy, hope, resilience, and optimism each have multiple emotional and cognitive functions, one of which is to enhance organizational entrepreneurship. Many studies have shown that people with high psychological capital not only have a lot of resistance and perseverance problems, but also because of their positive mental-cognitive space, they often find more productive solutions to problems. They find and implement it. While they have a positive view of what they have achieved through effort (Lutz et al., 2008; Rensch et al., 2010; Delige et al., 2010), such a view can be acknowledged when one's self-efficacy and hope in the individual. At a high level, the individual is seen more favorably in the organization because of the feeling of empowerment and expectation of positive outeomes and consequences of creativity and, consequently, organizational entrepreneurship. In addition, when hope is high in self-efficacy among organizational staff, the level of organizational entrepreneurship is enhanced. According to the results of the research from the practical viewpoint of faculty members can provide psychological capital training among their employees by providing consulting facilities or by holding workshops and in addition to adding capital. Your intangible, yet valuable enterprise benefits from its positive benefits and implications for the development and improvement of organizational entrepreneurship.

\section{Sources}

Antonic, B - Hisrich, R.D. (2003)"Clarifying the intrapreneurship concept", Journal of Small Business and Enterprise Development, Vol.10, No. 1, pp. 724.

Bakker, A. B. \& Schaufeli. W. B. (2008). Positive organizational behavior: Engaged employees in flourishing organizations. Journal of Organizational Behavior (29), 147-154. 
Delahaij, A., Gaillard, C., \& Van Dam, P. (2010). Hope and hardiness as related to Life satisfaction. The Journal of Positive Psychology ,3 (8): 171-179.

Farhangi, Ali Akbar; Safarzadeh, Hesti (2007). Entrepreneurship: Concepts, Theories, Methods and Applications, Tehran: Institute of Social Affairs.

Haji Karimi, Abbas Ali; Marjan Farjian (1999). Human, Social and Emotional Capital Management with an Effective Approach to Job Success: A Case Study of Bank Mellat, Public Management Journal, Volume 1, Number 4.

Hodges. Timothy D. (2010) An experimental study of the impact of psychological capital on performance engagement and the contagion effect.A Dissertations and Thesesfrom the College of Business Administration. University of Nebraska

Luthans, F, Avolio, B.J (2007). Positive psychological capital: Measurement and relationship with performance and satisfaction, Personnel Psychology, 60

Seyed Abadi, Malvak (2008). Social Capital and Entrepreneurship, Department of Cultural and Social Research, Research Institute of Expediency, Strategic Research Institute, Journal No. 12. Kuratko, Donald $₫$ F, Hodges $~$ Richard, M (2004). A Contemporary Approach to Entrepreneurship, Translated by Mehrabi Agent, Volume 1, Issue 5, Ferdowsi University of Mashhad Publications.

Luthans, F., Avey, J. B., Avolio, B. J., \& Peterson, S. J. (2010). The development and resulting performance impact of positive psychological capital. Human Resource Development Quarterly,21(1), 41-67.

Luthans, F., \& Youssef, C. (2007)Emerging positive organizational behavior.Journal of Management, 33(3), 321-349.

Silva,v (2010). The Contribution of Psychological Capital to Entrepreneurs Success during Recessionary Times. Submitted to the nonrefereed stream - New Zealand Applied Business Educators Conference27\& 28 September 2010 Napier. 